\title{
Erratum to: Impact of old age on patient-report outcomes and cost utility for anterior cervical discectomy and fusion surgery for degenerative spine disease
}

\author{
Silky Chotai ${ }^{1,2} \cdot$ Scott L. Parker ${ }^{1,2}$ J. Alex Sielatycki ${ }^{1,2} \cdot$ Ahilan Sivaganesan $^{1,2}$. \\ Harrison F. Kay ${ }^{1,2} \cdot J^{\prime}$ oseph B. Wick ${ }^{1,2}$ Matthew J. McGirt ${ }^{3}$ - Clinton J. Devin ${ }^{1,2}$
}

Published online: 17 February 2017

(c) Springer-Verlag Berlin Heidelberg 2017

\section{Erratum to: Eur Spine J}

DOI 10.1007/s00586-016-4835-3

In the original article, one of the co-author's given name has been published incorrectly. The correct given name should be Harrison F.

The online version of the original article can be found under doi:10.1007/s00586-016-4835-3.

Clinton J. Devin

clintondevin@gmail.com

1 Department of Orthopedics Surgery, Vanderbilt Spine Institute, Vanderbilt University School of Medicine, Vanderbilt University Medical Center, Medical Center East, South Tower, Suite 4200, Nashville, TN 37232-8774, USA

2 Department of Neurological Surgery, Vanderbilt University Medical Center, Nashville, TN, USA

3 Department of Neurological Surgery, Carolina Neurosurgery and Spine Associates, Charlotte, NC, USA 